\title{
Cameroonian Dentists' Opinion On Training And Quality Of Dental Services Rendered By Dental Auxiliaries
}

\begin{abstract}
Authors: Agbor MA ${ }^{1}$ (BDS, MSc. Dent), Azodo CC ${ }^{2}$ (BDS, MSc, MPH) 1-Dental Department, Nkwen Baptist Health Centre, Bamenda, Cameroon 2-Department of Periodontics, University of Benin Teaching Hospital, Nigeria. Corresponding author: Dr C.C. Azodo, Department of Periodontics. University of Benin Teaching Hospital New Dental Complex P.M.B 1111 Ugbowo Benin-City, Edo State Nigeria 300001. E-mail: clementazodo@yahoo.com Phone: +2348034051699
\end{abstract}

\section{Abstract}

\section{Objective}

To assess Cameroonian dentists' opinion on training and quality of dental services rendered by dental auxiliaries.

\section{Material and Methods:}

The questionnaire-based cross-sectional survey was conducted amongst randomly selected dentists from six provinces in Cameroon in the first quarter of 2010 .

\section{Results}

More than half (51.4\%) of the 37 respondents have worked with dental auxiliaries for more than 4 years with higher interaction between the respondents and dental therapists (59.5\%). Majority approved scaling and polishing and tooth extraction, few approved root canal therapy and none approved minor surgical procedure like salivary stone removal for the dental auxiliaries. Most respondents (86.5\%)

\begin{abstract}
agreed that dental auxiliaries work well with 30 (81.1\%) opining that the quality of services rendered by the dental auxiliaries were very satisfactory. A total of 15 (41\%) of the respondents thought that dental therapists should work in specific areas with $80 \%$ recommending rural areas. Majority of the respondents $30(81.1 \%)$ thought that dental auxiliaries are important in oral health care delivery in Cameroon and 33 (89.2\%) of the respondents thought that government should continue the training of dental auxiliaries.
\end{abstract}

\section{Conclusion}

The study revealed high level of interactions between dentists and dental auxiliaries in Cameroon. The respondents' opinions about dental auxiliaries were mostly positive. There existed variability in opinion of respondents about procedures that dental auxiliaries should perform. The is need for establishment of regulatory agency which would tap and harmonize all the derivable potential from dental auxiliaries.

\section{Introduction}

Cameroon is a Central African country with a 2009 estimated population of 18.9 million people and a population growth rate of $2.19 \%$ (1). The country's per-capita GDP was estimated as US\$2,300 in 2008. It has no dental school and only 147 actively practicing dentists registered with Cameroon Dental Association. The DMFT among 12 year olds is higher than many other African countries (2). With the growing population, limited resources, shortage of manpower and an abundance of dental diseases, services of dental auxiliaries are greatly needed to help meet the demand for services.

Utilization of dental auxiliary personnel is necessary for the provision of adequate oral health services to meet societal demands. By performing jobs formally handled by dentists, the auxiliary worker frees the dentist for complex tasks and thereby ensures a greater total supply of services. The greater use of paraprofessionals has resulted in greater outputs of services by professionals in Dentistry, Medicine and Law (3). It has been found from research that dentists work more efficiently and ef- fectively using these auxiliaries in their dental practice (4-6). In private dental surgeries in Kenya, improving the efficiency in patient's management was the main reason for the utilization of dental auxiliaries (5).

The objective of the study was to assess the dentist's opinion on quality of dental services and training of dental auxiliaries in Cameroon.

\section{Materials and Methods}

This research was conducted as a descriptive crosssectional survey of dentists working in six provinces in Cameroon. The list of registered dentists obtained from Cameroon Dental Association showed that 143 out of 147 dentists in Cameroon work in the six provinces. Every third dentist from the list of registered dentists in the six provinces was selected using systematic sampling technique. A total of 47 questionnaires were administered and 37 dentists responded giving an overall response rate of $78.7 \%$.

The 37 dentists that responded had a mean age of 38 \pm 10 years. Age range was 27-57 years; 14 females and 
23 males. Of the 37 dentists, 32 (86.5\%) worked in urban areas while $5(13.5 \%)$ worked in the rural areas. A self-administered bilingual (English and French) questionnaire was used to collect information on demography, the type of auxiliaries working with them, their satisfaction with the work of auxiliaries under their supervision, areas of dissatisfaction with the work, areas therapist should be assign to work, whether they should work alone, and if more of them should be trained and their recommendations. Ethical clearance to carry out the study was obtained from the respective provincial organs of the Cameroonian Ministry of Public Health in the six provinces. Informed consent was obtained from the participants after being informed of the objective of the study and assured of strict confidentiality of their responses. Participation was voluntary and no incentive was declared. Epi-info version Epi 3.1.5 was used for data analysis. Test for significance was performed using Chi square. $\mathrm{P} \leq 0.05$ was considered significant.

\section{Results}

The proportion of the respondents who had worked with dental auxiliaries, dental therapists, dental surgery assistants, dental technicians and dental aids was 100\%, $59.5 \%, 43.2 \%, 45.9 \%$ and 5.4\% respectively (Fig. 1). More than half $(51.4 \%)$ of the respondents had worked with auxiliaries for more than 4 years. Others had worked for 4 years $(18.9 \%), 3$ years $(16.2 \%)$, 2 years $4(10.8 \%)$ and unspecified duration $(2.7 \%, \mathrm{n}=1)$. Most $(81.1 \%)$ of the respondents $(n=30)$ opined that the quality of services rendered by the dental auxiliaries was very satisfactory (Figure 2). All the respondents did not approve auxiliaries carrying out minor surgery while 24 (64.9\%) and $6(16.2 \%)$ of them (64.9\%) did not approve auxiliaries performing root canal therapy and tooth extraction respectively (Table 1$)$.

About one-third, 12 (32.4\%) of the respondents had the impression that dental auxiliaries are important (Table $2)$. Most of the respondents $(86.5 \%)$ agreed that dental auxiliaries work well and 15 (41\%) of the respondents thought that dental therapists should work in specific areas with $80 \%$ recommending rural areas. Some respondents (43.2\%) approved that dental auxiliaries should be allowed to work alone. Thirty respondents thought that dental auxiliaries were important in oral health care delivery in Cameroon and thirty three supported continued training of dental auxiliaries by the government

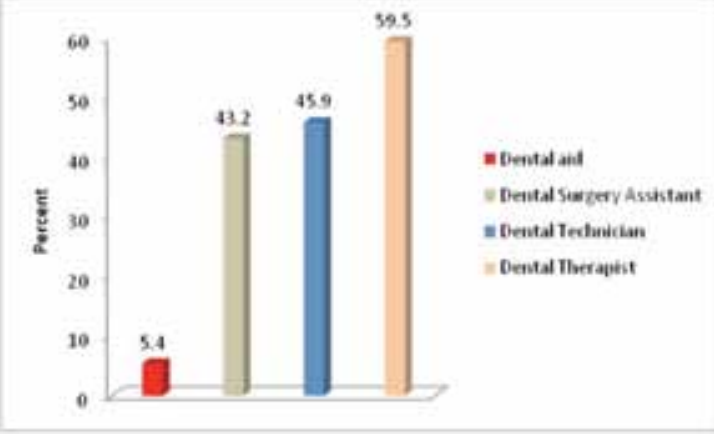

Figure 1: types of dental auxiliary that respondents have worked with

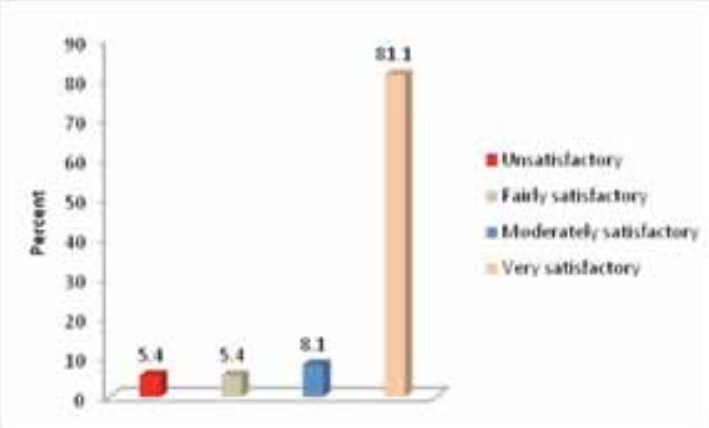

Figure 2: respondents' opinion of the quality of services rendered by dental auxiliaries

(Table 3).

\section{Discussion}

Teamwork is essential for the provision of contemporary, high quality oral health care (7). The present trend in dentistry is toward increased auxiliary utilization and improved methods in the delivery of health care. The experiences of majority of the respondents with different categories of dental auxiliaries reflect the significance of dental auxiliaries in the oral healthcare delivery and applicability of teamwork in Cameroon oral healthcare delivery. The increased interactions with dental therapists may be due to their valuable role in preventing oral diseases by performing meticulous scaling and polishing and oral hygiene instructions (8).

Dental auxiliaries are able to provide dental care of acceptable quality. The efficient utilization of dental auxiliaries usually results in decreased cost and increased productivity for the community. In this study, $86.5 \%$ 


\section{Cameroonian Dentists' Opinion On Training And Quality Of Dental Services Rendered By Dental Auxiliaries Agbor MA, Azodo CC}

\begin{tabular}{lll} 
Procedure & Yes (\%) & No (\%) \\
\hline Tooth extraction & $31(83.8)$ & $6(16.2)$ \\
\hline Root Canal Therapy & $13(35.1)$ & $24(64.9)$ \\
\hline Scaling and polishing & $36(97.3)$ & $1(2.7)$ \\
\hline Minor oral surgery like stone removal & $0(0.0)$ & $37(100.0)$ \\
\hline
\end{tabular}

Table 1: procedures approved for dental auxiliaries by the respondents

\begin{tabular}{lll} 
General opinion & Frequency & Percent \\
\hline They should work in rural areas & (no.) & (\%) \\
\hline They are important, dentists cannot work alone & 6 & 16.2 \\
\hline They need better training & 12 & 32.4 \\
\hline They are too young & 7 & 18.9 \\
\hline They should respect themselves & 9 & 24.3 \\
\hline Total & 3 & 8.1 \\
\hline
\end{tabular}

Table 2: respondents'general opinion about dental auxiliaries

Majority of the respondents approved scaling and polishing and tooth extraction, few approved root canal therapy and none approved minor surgical procedure like salivary stone removal for dental auxiliaries. Variability of the opinions of the respondents on procedures that can be performed by the dental auxiliaries reflects the diversity in the training of the respondents as all the dentists in Cameroon are trained in different countries of the world. In private dental surgeries in Kenya, delegation was done primarily based on dental auxiliaries' capability to perform the procedure and meet the set standards (5). This reflects an obvious need for a consensus among the dentists in order to standardize the job description of dental auxiliaries and establish a dental auxiliary regulatory agency in the long run.

\begin{tabular}{lll}
\hline Questions & Response \\
\hline Do dental auxiliaries do their work well? & Yes (\%) & No (\%) \\
\hline Do you think that dental therapist should work in specific locations? & $152(86.5)$ & $5(13.5)$ \\
\hline Do you think the dental therapist should work alone? & $22(59.5)$ \\
\hline Do you think that dental auxiliaries are important in & $16(43.2)$ & $21(56.8)$ \\
\hline oral healthcare delivery in Cameroon & $30(81.1)$ & $7(18.9)$ \\
\hline Do you think the government should continue training them? & $33(89.2)$ & $4(10.8)$ \\
\hline
\end{tabular}

Dental auxiliaries are valuable members of the dental care team and play a significant role for oral healthcare delivery. A significant proportion $(81.1 \%)$ of the respondents agreed that dental auxiliaries were important in oral healthcare delivery in Cameroon which may be the reason why $89.2 \%$ the respondents supported their continued training. Almost half the dentists (41\%) believe auxiliaries should work in a spe-

agreed that respondents work well and $81.1 \%$ declared the quality of services rendered by dental auxiliaries as very satisfactory. Earlier reports have indicated that irreversible dental treatment carried out by dental therapists did not differ from that of dentists (10). A review more than 3 decades ago showed that dental auxiliaries can, with the proper training, perform selected reversible and irreversible dental procedures at an acceptable level of quality (10). cific locality because of the needs with $80 \%$ suggesting working in rural areas. This may compensate the inequitable distribution of dental manpower. More than half $56.8 \%$ of the respondents agreed operative auxiliaries like therapists should work under supervision and sustained training. This is lower than $84 \%$ of general dental practitioner in Udaipur, India who thought that direct supervision was necessary although the reasons for that were not sought in that research (7). 


\section{Conclusion}

The study revealed high level of interactions between dentist and dental auxiliaries in Cameroon.

The respondents' opinions about dental auxiliaries were mostly positive. There existed variability in opinion of respondents about procedures that dental auxiliaries should perform. There is need for establishment of regulatory agency which would harmonize all the derivable potential from dental auxiliaries.

\section{References}

1. Wikipedia. Demographics of Cameroon. http://en.wikipedia. org/wiki/Demographics_of_Cameroon. Accessed 01 $\backslash 01 \backslash 10$

2. WHO Oral Health Country/Area Profile Programme. Global Caries burden for 12-year-old age group. http://www. whocollab.od.mah.se/afro.html. Accessed $01 \backslash 01 \backslash 10$

3. MacBride O. Restrictive licensing of dental paraprofessionals. Yale Law Journal. 1974; 83: 806-826.

4. Amer ME. Use of operating dental auxiliaries for school age children. University of Sydney Diploma in Public Health Dentistry Thesis. 1986.

5. Kaimenyi JT, Guthua SW, Wakiaga J, et al. Utilization of dental auxiliaries in private dental surgeries in Kenya. East Afr Med J. 1994; 71(12):811-5.

6. Gercsak JR. A study of job satisfaction and turnover of dental auxiliaries in British Columbia. Simon Fraser University Master of Business Administration (MBA) Thesis 1976.

7. Kulkarni S, Jain M, Mathur A, et al. General dental practitioners knowledge and attitudes towards employing dental hygienist or surgery assistant in India. The Internet J of Dent Sc. 2009 Number 1.

8. Ohrn K. The role of dental hygienists in oral health prevention. Oral Health Prev Dent. 2004; 2 Suppl 1:277-81.

9. Bolin K A. Assessment of treatment provided by dental health aide therapist in Alaska. A pilot study. J Am Dent Assoc. 2008; 139 (12):1585.

10. Sisty NL, Henderson WG, Paule CL. Review of training and evaluation studies in expanded functions for dental auxiliaries. J Am Dent Assoc. 1979; 98(2):233-48. 